\title{
Efektivitas Konseling Pasien Hipertensi Terhadap Perilaku Kepatuhan Berobat
}

\section{Effectiveness of Counseling to Hypertension Patients toward Treatment Compliance Behavior}

\author{
Nur Sefa Arief Hermawan ${ }^{(1)}$, Ditha Zakaria ${ }^{(1)}$, Mareza Yolanda Umar ${ }^{(2)}$, Riskawati $^{(1)}$ \\ ${ }^{(1)}$ Prodi Kesehatan Masyarakat, FakultasKesehatan Universitas Mitra Indonesia \\ ${ }^{(2)}$ Prodi D3 Kebidanan Universitas Aisyah Pringsewu Lampung \\ Korespondensi Penulis: Nur Sefa Arief Hermawan, Prodi Kesehatan Masyarakat \\ Fakultas Kesehatan, Universitas Mitra Indonesia \\ Email : sefa@umitra.ac.id
}

\begin{abstract}
ABSTRAK
Hipertensi atau tekanan darah tinggi adalah salah satu faktor risiko yang paling berpengaruh terhadap kejadian penyakit jantung dan pembuluh darah. Di Indonesia hipertensi telah mencapai lebih dari 2 juta kasus per tahun. Seperti yang kita ketahui bersama bahwa saat ini penyakit hipertensi sudah menjadi salah satu penyakit tidak menular yang perlu mendapat perhatian serius dari pemerintah dan juga masyarakat pada umumnya karena telah menjadi penyebab kematian terbesar di Indonesia. Kepatuhan masyarakat dalam hal ini pasien hipertensi sangat dibutuhkan karena bias mengurangi risiko komplikasi yang ditimbulkan. Tujuan penelitian ini untuk mengetahui efektivitas konseling pasien hipertensi terhadap perilaku kepatuhan berobat sebelum dan sesudah diberikan konseling. Desain penelitian ini menggunakan Pre - Eksperimental dengan rancangan pre test - post test one group design. Populasi penelitian adalah pasien hipertensi yang berjumlah 430 orang, sedangkan sampel penelitian adalah 54 orang dengan menggunakan metode purposive sampling dan harus memenuhi kriteria inklusi dan eksklusi untuk terpilih menjadi sampel. Analisis skor pre test dan post test serta paired t test digunakan dalam penelitian ini. Setelah diberi perlakuan konseling menunjukkan bahwa dari 54 responden diperoleh nilai rata-rata pre-test adalah sebesar 5,04 dan nilai post-test sebesar 7,02 (ada perbedaan 1,981). Adapun uji t diperoleh nilai $p$ value sebesar 0,00 atau $<0,05$ yang berarti terdapat perbedaan kepatuhan pengobatan pasien hipertensi sebelum dan sesudah konseling yang berarti konseling efektif. Hal ini dapat disimpulkan bahwa konseling berperan dalam perubahan perilaku kepatuhan berobat pasien hipertensi di Puskesmas Fajar Bulan tahun 2018.
\end{abstract}

Kata kunci: Konseling, Kepatuhan Pengobatan, Hipertensi

\section{ABSTRACT}

Hypertension or high blood pressure is one of the most significant risk factors in the incident oof heart disease and blood vessels. In Indonesia, hypertension has more than 2 million cases per year. As we know together, hypertension is now among non-communicable diseases that need serious attention from both governments and the general public because of being the leading cause of death in Indonesia. Public compliance with these hypertensive patients is needed most because their bias reduces the risk of complications. The purpose of this study is to know the effectiveness of hypertensive patient counseling on precautionary obedience behavior before and after counseling is given. The design of this study uses pre-experimental with pre-test and post-test one group design. The research population is a hypertensive patient amount to 430 people, while the study samples are 54 by using a purposive sampling method using the inclusion and exclusion samples. Analysis of pre-test and posttest scores and paired t-test were used in this study, after being given counseling treatment showed that from 54 respondents the average pre-test score was 5.04 and the post-test score was 7.02 (there was a difference of 1.981). The t-test obtained a p-value of 0.00 or $<0.05$, which means that there are differences in treatment compliance of hypertensive patients before and after counseling, which means effective counseling. It can be concluded that counseling plays a role in changing the behavior of hypertension treatment compliance patients at Fajar Bulan Health Center in 2018.

Keywords: Counseling, Medication Adherence, Hypertension 


\section{PENDAHULUAN}

Hipertensi disebut juga dengan nama tekanan darah tinggi. Biasanya hipertensi didefinisikan sebagai tekanan darah di atas 140/90, dan dianggap parah jika tekanan di atas 180/120. Kriteria hipertensi yang digunakan pada penetapan kasus merujuk pada kriteria diagnosis Joint National Committee (JNC) VII 2003, yaitu hasil pengukuran tekanan darah sistolik $\geq 140 \mathrm{mmHg}$ atau tekanan darah diastolik $\geq 90 \mathrm{mmHg}$ (Riskesdas, 2018).

Hipertensi sering kali tidak menunjukkan menimbulkan gejala sehingga disebut sebagai silent killer, sementara tekanan darah yang terus menerus tinggi dalam jangka waktu lama dapat menimbulkan komplikasi diantaranya penyakit jantung dan stroke. Oleh karena itu, hipertensi perlu dideteksi secara dini yaitu dengan melakukan pemeriksaan tekanan darah secara berkala (Kemenkes RI, 2015).

Hasil Riset Kesehatan Dasar tahun 2018, prevalensi kejadian hipertensi berdasakkan hasil pengukuran penduduk usia 18 tahun sebesar 34,1\%, tertinggi berada di Bangka Belitung (30,9\%), sedangkan prevalensi terendah di Papua sebesar (22,2\%). Untuk propinsi Lampung prevalensi hipertensi sebesar $24 \%$. Hipertensi terjadi pada kelompok umur 31-44 tahun (31,6\%), umur 45-54 tahun $(45,3 \%)$, umur 55-64 tahun (55,2\%) (Riskesdas, 2018).

Berdasarkan Profil Kesehatan Puskesmas Fajar Bulan Lampung Barat terjadi kenaikan kunjungan penderita hipertensi di wilayahnya dimana total kunjungan pasien hipertensi tahun 2016 sebanyak 389 orang meningkat pada tahun 2017 menjadi 430 orang. Begitu juga dalam dua bulan terakhir jumlah kunjungan hipertensi pada bulan Januari 2018 sebanyak 38 orang meningkat pada Februari 2018 sebanyak 53 orang (Puskesmas fajar bulan, 2015).

Penderita hipertensi merupakan salah satu pasien yang harus diberikan konseling agar patuh terhadap pengobatan yang dijalani, karena hipertensi merupakan penyakit yang secara pelan-pelan dapat menimbulkan kematian karena payah jantung, infark miokard, stroke atau gagal ginjal. Dengan demikian pemeriksaan tekanan darah secara teratur memiliki arti penting dalam perawatan hipertensi (Mursal, 2016).

Kepatuhan menjalani pengobatan sangat diperlukan untuk mengontrol tekanan darah serta mencegah terjadinya komplikasi. Kepatuhan pasien berpengaruh terhadap keberhasilan suatu pengobatan. Hasil terapi tidak akan mencapai tingkat optimal tanpa adanya kesadaran diri pasien itu sendiri, bahkan dapat mengakibatkan kegagalan terapi, serta dapat pula menimbulkan komplikasi yang sangat merugikan penderita dan pada akhirnya akan berakibat fatal (Pratiwi, 2011).

Penelitian yang dilakukan oleh Hermawan dan Novariana (2018) di Puskesmas Kedaton Bandar Lampung dengan populasi penelitian pada penderita hipertensi yang berobat di Puskesmas Kedaton menunjukkan bahwa penurunan rata-rata tekanan sistole pada penderita hipertensi yang diberikan sari mentimun adalah $14,00 \mathrm{mmHg}$ sedangkan rata - rata tekanan diastole pada penderita hipertensi yang diberikan sari mentimun adalah 10,00 $\mathrm{mmHg}$.

Komplikasi hipertensi diantaranya adalah infark miokard, gagal ginjal ensefalopati (kerusakan otak), dan stroke. Upaya pencegahan dan pengendalian hipertensi dilaksanakan dengan perilaku CERDIK yaitu : Cek kesehatan secara berkala, Enyahkan asap rokok, Rajin beraktifitas fisik, Diet yang sehat dengan kalori seimbang, Istirahat yang cukup, dan Kelola stress (Kemenkes RI, 2012).

Berdasarkan data rekam medik Puskesmas Fajar Bulan Lampung Barat pada bulan Februari 2018 didapatkan hasil bahwa dari 10 orang penderita hipertensi 7 diantaranya tidak patuh dalam berobat (70\%) dan 3 orang diantaranya patuh dalam berobat. Selain itu didapatkan juga informasi bahwa penderita hipertensi umumnya berobat ketika sudah mengalami gejala yang dapat mengganggu aktifitas seperti, sakit kepala, menurunnya fungsi penglihatan. Hal inilah yang menjadi dasar peneliti untuk melakukan penelitian ini dengan tujuan untuk mengetahui efektivitas konseling terhadap perilaku penderita hipertensi sebelum dan sesudah konseling. 


\section{SUB YEK DAN METODE}

Jenis penelitian ini adalah penelitian kuantitatif dengan menggunakan desain pre eksperimental dengan pendekatan pre testpostest one group design. Desain pre test-post test one group ini dilakukan pada satu kelompok dengan menggunakan pre test (test awal) sebelum melakukan perlakuan dan dilanjutkan memberikan posttest (test akhir) setelah melakukan perlakuan. Populasi penelitian adalah pasien hipertensi yang berjumlah 430 orang. Sampel penelitian berjumlah 54 orang yaitu pasien hipertensi yang berkunjung ke UPT Puskesmas Fajar Bulan Kabupaten Lampung Barat.

Dalam penelitian ini peneliti memilih sampel dengan metode purposive sampling dengan menggunakan kriteria inklusi dan eksklusi yang telah ditetapkan peneliti. Data primer penelitian ini didapat dari hasil wawancara terhadap responden yang ada. Analisis data bivariat yang digunakan menggunakan uji statistik uji $\mathrm{t}$ dependen (Paired t-test) dengan tingkat kemaknaan sebesar 5\% $(\alpha=0,05)$.

\section{HASIL}

Distribusi frekuensi yang diteliti dalam penelitian ini adalah skor kepatuhan berobat pasien hipertensi sebelum dan sesudah dilakukan konseling. Selanjutnya, analisis statistik dengan uji t dependen (paired t-test) dilakukan untuk melihat perubahan perilaku kepatuhan berobat pasien hipertensi dengan membandingkan kondisi sebelum dan sesudah dilakukan post test dengan sebagai berikut :

\section{Tabel 2. Distribusi Frekuensi Kepatuhan Berobat Responden Sebelum dan Sesudah Dilakukan Konseling}

\begin{tabular}{lcclll}
\hline \multicolumn{1}{c}{ Pre-test } & \multicolumn{4}{c}{ Post-test } \\
\hline $\begin{array}{l}\text { Perilaku } \\
\text { Kepatuhan } \\
\text { berobat }\end{array}$ & $\mathbf{n}$ & $\mathbf{( \% )} \begin{array}{l}\text { Perilaku } \\
\text { Kepatuhan } \\
\text { berobat }\end{array}$ & $\mathbf{n}$ & $\mathbf{\%}$ \\
\hline Tidak patuh & 40 & 74,1 & Tidak patuh & 29 & 53,7 \\
\hline Patuh & 14 & 25,9 & Patuh & 25 & 46,3 \\
\hline Jumlah & $\mathbf{5 4}$ & $\mathbf{1 0 0}$ & Jumlah & $\mathbf{5 4}$ & $\mathbf{1 0 0}$ \\
\hline
\end{tabular}

Tabel 3. Uji T Dependen (Paired T-Test)

\begin{tabular}{cccccc}
\hline Variabel & Mean & SD & SE & p value & N \\
\cline { 1 - 4 } Pre test & 5,04 & 1,098 & 0,149 & \multirow{2}{*}{0,00} & \multirow{2}{*}{54} \\
\cline { 1 - 4 } Post test & 7,02 & 1,584 & 0,216 & & \\
\hline
\end{tabular}

\section{DISKUSI}

Sebanyak 54 responden diberikan perlakuan konseling melalui media leaflet dan wawancara dengan kuesioner yang telah disediakan oleh peneliti. Dari hasil penelitian diperoleh nilai mean pre test 5,04 sedangkan pada pos ttest 7,02 (terdapat selisih sebesar 1,98) sehingga dapat diketahui terjadi peningkatan perilaku kepatuhan sebagai efek dari intervensi konseling yang diberikan tentang pada pasien hipertensi. Adapun nilai minimum saat pre test sebesar 3,00 dan pada post test sebesar 4,00 sedangkan nilai maksimum saat pretest 8,00 dan post test sebesar 9,00.

Setelah didapat hasil tersebut peneliti melanjutkan dengan uji statistik $\mathrm{t}$ dependen (paired $t$-test). Hal ini dilakukan untuk melihat perubahan perilaku kepatuhan dengan membandingkan kondisi sebelum dan sesudah diberikan konseling. Dimana nilai signifikan (2-tailed) yang dihasilkan adalah 0,00 yang berarti terdapat perbedaan perilaku kepatuhan berobat pasien hipertensi sebelum dan sesudah diberikan perlakuan konseling. 
Adanya perbedaan perilaku kepatuhan berobat pasien hipertensi sebelum dan sesudah diberikan perlakuan konseling diduga dipengaruhi oleh proses melihat, membaca dan mendengarkan konseling yang telah diberikan. Hal ini ditunjukkan dengan perubahan respon pasien untuk memeriksakan kesehatannya setelah dua minggu pasca konseling diberikan pasien hipertensi di Puskesmas Fajar Bulan tahun 2018. Hal ini menunjukkan bahwa konseling berperan dalam perubahan perilaku kepatuhan berobat pasien hipertensi di Puskesmas Fajar Bulan tahun 2018.

Hasil penelitian ini sejalan dengan penelitian Mursal tentang Konseling terhadap kepatuhan berobat penderita hipertensi, dimana hasil penelitiannya menunjukkan ada pengaruh konseling terhadap kepatuhan berobat penderita hipertensi (Mursal, 2016). Pada Penelitian yang dilakukan di Puskesmas Fajar Bulan ini menunjukkan bahwa konseling cukup efektif untuk meningkatkan kepatuhan berobat pada pasien hipertensi, dimana sebelum dilakukan konseling pasien yang patuh berobat hanya sebanyak 14 orang $(25,9 \%)$, sedangkan sesudah dilakukan konseling pasien hipertensi yang patuh berobat meningkat menjadi 25 orang $(46,3 \%)$.

Perubahan perilaku ini juga dapat dipengaruhi oleh tingkat pendidikan responden. Pendidikan seseorang mempengaruhi cara pandang terhadap diri dan lingkungannya. Karena itu akan berbeda sikap konseling yang berpendidikan tinggi dibandingkan dengan konseling yang berpendidikan rendah dalam menyikapi proses dan berinteraksi selama dalam konseling. Tingkat pendidikan formal yang tinggi pada umumnya memudahkan pasien untuk menerima konseling yang diberikan oleh konselor

\section{KESIMPULAN}

Terdapat perbedaan yang bermakna tentang kepatuhan berobat penderita hipertensi sebelum dan sesudah mendapatkan konseling dari hasil uji $t$ berpasangan diperoleh nilai $p$ value $=0,000(\mathrm{p}<0,05)$. Dari hasil penelitian ini diharapkan penelitian selanjutnya dapat meneliti mengenai efektivitas perbedaan konseling di Puskesmas dan di rumah dengan kepatuhan pengobatan penderita hipertensi dan pemberian bimbingan konseling secara berkesinambungan.

\section{DAFTAR PUSTAKA}

Hermawan, N.S.A., Novariana, N., 2018. Terapi Herbal Sari Mentimun untuk Menurunkan Tekanan Darah pada Penderita Hipertensi. J. Aisyah J. Ilmu Kesehat. 3, 1-8. https://doi.org/10.30604/jika.v3i1.69

Kemenkes RI, 2015. Profil Kesehatan RI 2015. https://doi.org/10.1111/evo.12990

Kemenkes RI, 2012. Masalah Hipertensi di Indonesia.

Mursal, 2016. Konseling Terhadap Kepatuhan Berobat Penderita Hipertensi Counseling toward Medication Adherence of Hypertensive Patient. J. Ilmu Keperawatan.

Pratiwi, D., 2011. Pengaruh Konseling Obat terhadap Kepatuhan Pasien Hipertensi di Poliklinik Khusus RSUP DR. M. Djamil Padang. Univ. ANDALAS.

Puskesmas fajar bulan, 2015. profil puskesmas. Lampung Barat.

Riskesdas, 2018. Riset Kesehatan Dasar 2018. Kementrian Kesehat. Republik Indones. https://doi.org/1 Desember 2013 